\title{
FILOSOFIA COM A TERCEIRA IDADE A PARTIR DO CUIDADO DE SI: UMA ABERTURA AO SER EM SI
}

\author{
PHILOSOPHY WITH ELDELY PEOPLE STARTING CARING THEMSELVES:
} AN OPENNING TO THE BEENIG ITSELF

\author{
Alex Sander da Silva ${ }^{1}$ \\ Jéferson Luís de Azeredo ${ }^{2}$ \\ Paula de Oliveira ${ }^{3}$
}

\begin{abstract}
RESUMO
O presente artigo pretende fazer uma incursão reflexiva sobre o tema do cuidado de si na aproximação entre o conhecimento de filosofia de Martin Heidegger e Michel Foucault. Aqui pretende-se fazer uma reflexão sobre o que é a filosofia e seu papel nos contextos atuais, particularmente, em espaços não comuns da reflexão filosófica, a saber, grupos de pessoas idosas. Desse modo, num primeiro momento, traçamos algumas dimensões fundamentais do conhecimento filosófico de Heidegger, entendido como um saber crítico do pensar e agir humanos. Num segundo momento, destacamos o tema na perspectiva de Foucault num significado do cuidado e cultivo de si. Ambas discussões norteiam as configurações do projeto de extensão "A filosofia vai à terceira idade", cujo principal objetivo se configura em proporcionar uma alternativa para se pensar uma aproximação entre o conhecimento filosófico com pessoas idosas.
\end{abstract}

Palavras-chave: Filosofia; Idosos; Cuidado de Si; Heidegger; Foucault.

\begin{abstract}
The article want to present a reflective foray on the topic care of themselves in approach between the knowledge philosophy of Martin Heidegger and Michel Foucault. Here it is intended to reflect on the what is a philosophy and his role in the current contexts, particularly in spaces not common philosophical reflection, in the know, elderly groups. This way, in a first moment, we draw some philosophical knowledge fundamentals dimensions of Heidegger, understood to know critical thinking and human acting. In a second moment, we highlight the issue in Foucault's perspective a meaning care and self cultivation. Both discussions guide as extension project settings "Philosophy will for elderly", whose director goal is to provide sets a alternative to think approaching among the philosophical knowledge with elderly people.
\end{abstract}

Keywords: Philosophy; Elderly; Care of himself; Heidegger; Foucault.

\footnotetext{
${ }^{1}$ Professor do Programa de Mestrado em Educação - UNESC.

${ }^{2}$ Professor do Programa de Mestrado em Educação - UNESC.

${ }^{3}$ Acadêmica do curso de Artes Visuais da UNESC.
} 


\section{ASPECTOS INTRODUTÓRIOS}

Este trabalho tem sua origem após uma discussão feita sobre a necessidade de resgatar algumas questões mais antigas à filosofia, que têm sua base nas perguntas ditas "clássicas", como: quem sou eu? Quem é o outro? O que é verdade? etc. Discussões que pensou-se em também resgatar noutros espaços, que não são os comumente acadêmicos ou os institucionais, sabidamente já explorados pela filosofia. Com esta primeira intensão, de "sair dos espaços formais", as perguntas sobre onde se faz filosofia e quem a faz também repercutem, além de interrogar-se o que é a filosofia, pois mesmo tendo-se várias justificativas pelas academias e grandes filósofos como Husserl, Deleuze, Kant, Nietzsche... ou, até mesmo em outros ambientes em que a lógica, a argumentação e as ciências são explorados, nossa educação brasileira não alcança completamente o resultado de tornar a filosofia um pensamento válido e de uso fácil para a maioria dos iniciados, seja na educação básica seja nos cursos que têm filosofia em sua grade curricular, pois talvez o mais simples não é respondido ou esclarecido, o que é a filosofia, o que ela faz? Surge nossa primeira hipótese.

Aqui pretende-se fazer uma reflexão sobre o que é a filosofia e seu papel nos contextos atuais. Mais uma reflexão? Não apenas continuar ou tratar de modo diferente esta questão, mas aproximar a uma realidade que possibilita outra resposta, ou ainda, possibilita relacionar com um novo contexto, este atual, em que talvez não foi explorado, filosofia com os grupos idosos, ou assim chamados de Terceira Idade.

Nós professores, Alex Sander e Jéferson L. Azeredo, após alguns encontros pelo grupo GEFOCS $^{4}$, discutimos preliminarmente que havia uma possibilidade de iniciarmos um movimento filosófico com grupos que carecem até mesmo de outras discussões sociais, políticas e éticas. Movimento esse que contemplasse nossa proposta de fazer filosofia para fora dos muros universitários, em espaços não formais, e atender assim a grupos menos favorecidos no nosso atual contexto histórico. Grupos estes por vezes desprivilegiados por ações educacionais que, a nosso ver, deveriam ser os primeiros a possibilitar ou ampliar as formas de pensar e consequentemente de agir e ser.

Chegamos assim aos idosos como nosso público-alvo, primeiramente porque resgatamos as condições destes, e que são quali e quantitativamente demostrado por pesquisas (GUIMARAES, 2007), herdeiros de "esquecimento" e afastamento em vários campos do social, antes citados, o que, analisado historicamente, se deu diferente num passado mais

\footnotetext{
${ }^{4}$ O Grupo de Estudos e Pesquisas sobre Educação, Formação Cultural e Sociedade foi criado em 2011 e agrega professores e estudantes da graduação e pós-graduação na UNESC, estando vinculado ao Programa de PósGraduação em Educação (PPGE-UNESC).
} 
remoto, pois havia mais espaço para o idoso, não só em sua casa, mas em locais de decisão como política, negócios, estética.

Assim, as problematizações sobre o que é a filosofia, para os "não iniciados" no pensar filosófico, e com quem a fazemos, fez nascer a extensão: "Filosofia vai a Terceira Idade: cultivando o cuidado de si”, que vai ao encontro dessa realidade citada. Para a proposta de extensão, foram convidados os idosos que estão ligados à $\mathrm{AFASC}^{5}$, por já organizarem-se em locais e horários mais propícios ao tempo e condições que se adaptam as rotinas e horários nossos na Universidade, e que poderiam ser contemplados pelo edital de extensão da Unesc.

Hoje o projeto, já com quatro anos, colhe frutos que podem ser percebidos pelas acadêmicas-bolsistas, pelos idosos participantes e pelos coordenadores do projeto, que serão brevemente escritos/relatados em outro material para publicação. Neste trabalho, apresentaremos alguns conceitos e autores que fazem parte das discussões do projeto, que fundamentam as problematizações que são propostas aos grupos de idosos. Fazendo-se igualmente uma relação com a condição do idoso hoje, justifica-se a iniciativa quanto extensão e igualmente como pesquisa.

Assim, as reflexões que compõem este trabalho são decorrentes principalmente de uma pesquisa bibliográfica, com as obra "Ser e Tempo" (exatamente a primeira seção) e "Carta sobre o humanismo" de Martin Heidegger, e na relação com este autor, não apenas centrado pela leitura hermenêutica, Michel Foucault ${ }^{6}$, especificamente com o último volume da "História da Sexualidade III" e suas aulas no Collège de France, entre 1980 e 1982, parte delas reunidas no "A Hermenêutica do Sujeito", bem como sua obra "Microfísica do Poder". Portanto, aqui há o desafio em estabelecer uma aproximação entre o Dasein de Heidegger e o cuidado de si de Foucault, também com a ampliação de outros textos.

\section{O CULTIVO E CUIDADO DE SI: CONTRIBUIÇÕES DE MARTIN HEIDEGGER}

Um elemento que orienta o projeto de extensão "A filosofia vai a terceira idade" é a preocupação que se tem com a formação da condição do pensamento. Parte-se do pressuposto que para o pensar livre deve-se atentar para toda forma de "modelagem" que possa contrariar esta intensão, limitando a condição a uma unilateralidade. A hermenêutica de Martin Heidegger é uma forma que se pode estabelecer o contrário, um anti-pensamento acrítico,

\footnotetext{
${ }^{5} \mathrm{O}$ projeto de extensão se realiza com Grupos de idosos do município de Criciúma, vinculados a Associação Feminina de Assistência Social de Criciúma (AFASC).

${ }^{6}$ Destaca-se aqui que Foucault nem sempre pensou a subjetividade como possibilidade junto a uma autonomia. Nas duas primeiras fases: a Arqueológica, a Genealógica, apontava para o poder como única e total forma da constituição dos sujeitos, inferindo aí a linguagem como meio para tal. Só na terceira fase, é que a subjetividade sem controle começou a ser pensada.
} 
bem como, a reflexão da ideia de diluição de cada pessoa no conjunto de todas as pessoas, de modo que seria impossível perceber se quem está pensando é o "EU" ou são os outros. Projeto de esclarecimento que vem ao encontro da proposta mais embrionária desta extensão, que quer esclarecer o que subjulga, e por vezes o que dogmatiza, talvez como maior força, a própria cultura.

Este esclarecimento, Heidegger chama de compreensão, que é a constituição de simesmo, uma leitura do ser do ser-aí (2014, p. 206) e do mundo (mesmo parecendo que hajam conflitos na escrita de Heidegger, pois o mundo da ocupação (Besorge) e da solicitude (Fürsorge) para com as coisas (mundo) não apresenta nenhum traço de alienação e exploração como se vê com estruturas de análise marxista), levando em conta para ele que o ser está no mundo (O ser aí). Mas, é um mais do que levar em conta o mundo, é levar em conta que o ser está no mundo partindo-se assim para a afirmação de um ser que tem um cuidado consigo mesmo, o que podemos chamar, a partir de Heidegger, de um "cuidado fundamental do Dasein” (Sorge). Pois se o ser preocupar-se não com seu ser-aí e inserir-se apenas no fazer, usar, técnica... amar, proteger os outros, o cuidado é impróprio, orientado apenas pela bipartição ocupação-solicitude. Mas se o ser-aí para com o contato com o mundo e com os outros, este retorna a si mesmo.

Aqui temos uma justificação existencialista do projeto de extensão, pois uma resposta à vida em sua essência que se processa de uma existência parece responder a alguns problemas atuais, e concilia a própria história dos idosos que podem se perceber na relação de ser-história, ou seja, as escolhas de suas vidas mostram-se fundantes do seu ser, sou o que escolhi/optei. Heidegger permite estabelecer que qualquer tipo de cuidado do ser-aí seja uma preocupação a qual o Ocidente Moderno e ainda a Pós-modernidade deve-se fazer.

Se levarmos em conta o fundamento marxista, exclui-se o idoso dos processos de decisões, que se inscrevem a partir dos processos de produções, dando, assim, pouca ou nenhuma importância a eles. Estas questões são os nortes deste trabalho, e, articulados a elas, traça-se o objetivo: evidenciar a importância do cuidado de si para a constituição da ação filosófica hermenêutica que estimula o surgimento de sujeitos autênticos (na condição de mais velhos: idosos), que sejam capazes de colocar a sua herança cultural em suspeição e de assumir a construção de uma compreensão crítica e autônoma do "ser-aí".

Só é possível o exercício filosófico quando estabelecidos a abertura do ser-aí, que Heidegger sugere como liberdade. Neste movimento de fazer filosofia, já se pode apontar uma resposta ao que é a filosofia, aqui um pensamento que se constrói ao encontro do "ser do ente”. A abertura proposta por Heidegger já é um movimento filosófico e que também 
converge ao que é o projeto de filosofia com idosos que fazemos. Segundo Fernando Belo (1992, p. 18),

\begin{abstract}
Esta abertura está como que obturada no humano normal, pela preocupação (Sorge) que cada um não pode deixar de ter pela sua existência humana, melhor dito, na sua insistência preocupada com a sua manutenção e conservação quotidiana. A si mesmo só se apreende como ente no meio dos outros entes, que lhe estão em face e à mão. Ou seja, o homem normal não se apreende como totalidade no seu viver quotidiano, não se abre ao ser que o diferencia dos outros entes. É o que Heidegger designará como modo impróprio de ser (por vezes traduzido por inautêntico).
\end{abstract}

Sobre estas considerações, vê-se em Heidegger, quando escreve a Jean Beaufret, em 1947, logo após a Segunda Grande Guerra Mundial, a "Carta Sobre o Humanismo”, em que situa que a humanidade só se faz na meditação do homem, que fundamenta seu ser-aí capaz de preservar a verdade, pois ele é o ente que assim a porta $(2005$, p. 07). A abertura à meditação busca preservar sua humanidade. Desta definição que preserva a questão do ser, sugere a liberdade como saída e resposta. "Que o homem se questione sobre aquilo que venha a ser antes de qualquer definição ou ato" (ARAÚJO, 2011, p. 4). Este processo só pode ser relacionado ao cuidado de si, pois, se não é a própria pessoa agente deste processo quem mais o fará?

Os conceitos de vontade e desejo são colocados ao ser-aí como modos de operação para o cuidado. Somente o ser-aí dispõe de vontade e desejo, atribuindo posteriormente aos outros entes. A vontade é um querer que se projeta (poder-ser) ao um ente querido, a angústia que acompanha e disponibiliza esta "projeção" (HEIDEGGER, 2014, p. 258), é uma "realização da disposição sobre si mesmo" (STEIN, 2011, p. 117).

Ocupação e solicitude, antes citado na introdução deste texto, somente são possíveis devido à estrutura do ser-aí enquanto cuidado, pois, antecipando-se a-si, optando por possibilidades atualizáveis por meio de seu poder-ser (vontade), possibilita assim um outro contato (secundário) que é com os utensílios e os outros. O objeto e um outro ser-aí, se encontra no impessoal (HEIDEGGER, 2014, p. 262), assim, só pelo cuidado de-si, que se resume pela angústia de seu ser em débito ao ter-que-ser, se tem uma vontade (querer) tematizado, focado pelo ser-aí, já o contrário aniquila a possibilidade do ser-aí, que é o desejo.

Já o desejo é caracterizado como uma força sem escolhas, que se impulsiona pelo coletivo, pelo que pode vir sem se preocupar, esquematizar, tematizar, o desejo está para o só desejar. É um perder-se no meio. Nesse sentido adere-se pelo desejo à uma inclinação do seraí ao mundo que é somente impessoal, os outros ditam o que fazer; não há dúvidas ao verdadeiro, ao que se desejou. 
Se é pela vontade que se pode ter a abertura, a presença é apresentada ao poder-ser pertencente ao ser-aí como condição ontológica primordial (HEIDEGGER, 2014, p. 268). Poder-ser e presença estão intimamente relacionados, pois no poder-ser radica a possibilidade do ser-aí escolher determinadas possibilidades. Ou seja, é pelo conceito de presença que o seraí pode ser verdadeiramente livre, uma vez que, escolhendo o modo de ser que ele quer ser, define-se o seu ter-que-ser. Assim o cuidado do ser-aí, que é um ente jogado no mundo, é definido por ele mesmo, não existindo anteriormente qualquer regra histórica ou social como definição para o projetar.

A extensão "Filosofia vai à Terceira Idade" articula este pensamento no seu fazer, constituindo uma relação de temas e problemas filosóficos, em que o ser-aí é estabelecido como pano de fundo. Este pode ser, em similitude, relacionado com o que Foucault chama de “cuidado de si”, em que há uma verdade que só pode ser alcançada pelo sujeito reflexivo e esclarecido.

\section{FOUCAULT E O CUIDADO DE SI}

O cuidado de si também pode ser visto desde os tempos do helenismo e da antiguidade romana, ou até mesmo no cristianismo romano, mas, perdendo espaço no pensamento cartesiano, pois este último refaz o conhecer-se numa esfera racional e lógica, ou seja, acesso à verdade somente pelo conhecimento objetivo da realidade, do ser desqualificando o próprio cuidado de si (epiméleia heautô̂) (FOUCAULT, 2004).

A resposta que se dá ao que é filosofia vai ao encontro do cuidado de si tanto quanto do ser-aí heideggeriano, e é dessa transformação que possibilita-se uma outra realidade e, mais ainda, um outro ser. Para Foucault, se a filosofia é o pensamento que se interroga sobre o como é possível a verdade, como ter acesso a ela, situa-se portanto numa dimensão "espiritual", ou o que

que poderíamos chamar de "espiritualidade" o conjunto de buscas, práticas e experiências tais como as purificações, as asceses, as renúncias, as conversões do olhar, as modificações de existência, etc., que constituem, não para o conhecimento, mas para o sujeito, para o ser mesmo do sujeito, o preço a pagar para ter acesso à verdade (FOUCAULT, 2004, p. 19).

Diga-se que o acesso à verdade só é dada ao sujeito a um preço que põe em jogo o ser mesmo do sujeito tendo como consequência à exigência de uma conversão, uma transformação do sujeito. Para ele, esta conversão, esta transformação, que é um "segundo grande aspecto da espiritualidade" (FOUCAULT, 2004, p. 20) pode fazer-se sob diferentes formas, a primeira é um "arrancar" do sujeito de sua condição atual a partir da verdade que 
vem até ele e o ilumina; Foucault chama de éros (amor). Há também o que ele chama de trabalho, "de si para consigo", alcançado pelo perfazer do tempo e da paciência na atmosfera da ascese (áskesis). Somente pelo éros e pela àskesis, o sujeito moderno é capaz da verdade, de encontrar-se a si mesmo, de cuidar do que lhe é mais importante, ele mesmo. $\mathrm{Na}$ efetividade do aberto, ou como diz Heidegger, do Dasein, que se percebe que o ser espiritual, que não apenas recebe uma verdade ${ }^{7}$, mas que o "tranquiliza a alma",

[...] na verdade e no acesso à verdade há alguma coisa que completa o próprio sujeito, que completa o ser mesmo do sujeito e que o transfigura. Resumindo, acho que podemos dizer o seguinte: para a espiritualidade, um ato de conhecimento, em si mesmo e por si mesmo, jamais conseguiria dar acesso à verdade se não fosse preparado, acompanhado, duplicado, consumado por certa transformação do sujeito, não do individuo, mas do próprio sujeito no seu ser de sujeito (FOUCAULT, 2004, p. 21).

Outro acesso à filosofia, que não este que abre o ser a possibilidades e o permite ter SUA espiritualidade, inverte, como o citado "momento cartesiano" que usa a lógica e a objetividade para responder a tudo, ou ainda, a cristandade que institui o outro, o coletivo ou o não egoísmo como desqualificação do sujeito e consequentemente do seu movimento de "cuidado de si” (epiméleia heautoû).

O projeto de filosofia com os idosos resgata o valor do EU, do ser para longe da negação em prol de um grupo, de uma família, de uma empresa, de uma sociedade, nação, economia, igreja... Sem a renúncia, pode-se iniciar o processo de fazer filosofia, que fundamenta o projeto e o justifica enquanto necessário à vida.

O sentido que Heidegger e Foucault podem ser convergidos é a retomada desta ideia da Antiguidade, que razão e espiritualidade então associadas numa integral dimensão humana, numa resposta ontológica do sujeito que conhece. Pela hermenêutica de Heidegger, reabilitase a noção do cuidado de si, como convocação do ser-aí a voltar a si mesmo, na transformação contrária à "auto alienação", tão comum naqueles que aceitam de forma acrítica sua condição de "existir no mundo" e que, por este motivo, ficariam totalmente sujeitos ao controle da herança cultural que recebem.

Encontram-se os autores, Heidegger e Foucault, em que percebem o sujeito sob efeitos do mundo fatídico e consequentemente assujeitador; "o ser-aí se torna compreensível a partir de seu mundo" (HEIDEGGER, 1999, p. 113-148). Para Foucault, especialmente na "História da Sexualidade III", com o último livro "O cuidado de si”, o exercício espiritual é um domínio, são as técnicas que possibilitam tal cuidado. O que antes fora analisado por

\footnotetext{
${ }^{7}$ Aqui pode-se estabelecer Sartre como diferença de Heidegger, pois Sartre separa por completo este movimento platônico de verdade em relação à lembrança.
} 
Foucault, uso dos prazeres e sexo, agora se concentra no sujeito que se abre a outras possibilidades (FOUCAULT, 1985b). O novo eu produzido pelas novas relações políticas e de uma cultura que tem o "si" como foco das atenções, não encerra entorno de egoísmo ou isolamento, mas problematiza o "si", ou seja, há uma problematização de si para consigo mesmo; há uma nova "estilística da existência".

\section{CONSIDERAÇÕES FINAIS}

Um trabalho específico sobre filosofia e a terceira idade não é tão comum se levarmos em conta o modo como o conhecimento filosófico está inserido no cotidiano das pessoas. Geralmente, são adolescentes e jovens que tem um contato privilegiado com esse conhecimento no processo de sua formação escolar. Sendo que as pessoas que já encerraram e/ou não desenvolveram suas atividades escolares podem ter um contato muito esporádico com a filosofia.

O nosso interesse não inclui uma defesa simplesmente da criação de cursos de filosofia para as pessoas idosas. Diz mais respeito a uma retomada da tradição original da Acrópole para se pensar o envelhecimento humano, ou seja, no desenvolvimento da filosofia com a terceira idade com o espírito da tradição grega. Aquela filosofia que nasce nos espaços públicos, na praça, no ambiente democrático dos cidadãos livres.

Nesse sentido, a filosofia apresenta uma oportunidade para as pessoas idosas de um núcleo ético-pedagógico presente na tradição filosófica, como ponto de partida para busca de respostas para as questões sobre o sentido da vida. O sentido do envelhecer tomado como um compromisso do sujeito em suas relações. Assim, queremos salientar que a proposta desse trabalho de extensão, diz respeito ao "cultivo e cuidado de si" como condição de possibilidade para uma sociabilidade cooperativa e solidária dos indivíduos consigo e com os demais.

E temos plena consciência que é um projeto desafiador, e que, de forma "tímida", vem dando seus primeiros passos para sua viabilidade. Também se faz importante considerar que este desafio ainda continua como um projeto de extensão que põe a exigência do cuidado e do cultivo como ponto de partida e de chegada. Portanto, um envelhecimento baseado no cuidado e cultivo de si corresponde o anseio pelo exercício de conhecimento de si mesmo. 


\section{REFERÊNCIAS}

ARAÚJO, Bernardo G. Questões filosóficas contemporâneas: Heidegger e o humanismo. 2011.

BELO, Fernando. Heidegger pensador da terra. Coimbra: APF, 1992.

CHAIMOWICZ, Flavio. A saúde dos idosos brasileiros às vésperas do século XXI: problemas, projeções e alternativas. Rev. Saúde Pública, São Paulo, v. 31, n. 2, 1997.

FOUCAULT, Michel. História da sexualidade 2: o uso dos prazeres. Rio de Janeiro: Edições Graal, 1985a.

FOUCAULT, Michel. História da sexualidade 3: o cuidado de si. Rio de Janeiro: Edições Graal, 1985b.

HEIDEGGER, Martin. Sobre a essência da fundamentação. In: Os Pensadores: Heidegger. São Paulo: Nova Cultural, 1999.

HEIDEGGER, Martin. Ser e Tempo. 9 Ed. Petrópolis, RJ: Editora Vozes, 2014.

GUIMARAES, Elzimar Campos. Reflexão Sobre a velhice. CES Revista, Juiz de Fora, v. 21, p. 11-23, 2011.

STEIN, Ernildo. Introdução ao pensamento de Martin Heidegger. Porto Alegre: EDIPUCRS, 2011. 